\title{
MULTISENSORY FLOW EXPERIENCE THROUGH AUGMENTED-VIRTUAL REALITY INTERACTIVE TECHNOLOGY EDUCATION
}

\author{
Dr. Mirza Viquar Ahmed \\ Assistant Professor, Business Administration Department \\ Jubail University College, PO. Box 10074, Jubail Industrial City 31961 \\ Kingdom of Saudi Arabia
}

\begin{abstract}
The industry of education has appeared to be found as little bit slow at embracing the effectiveness and usefulness of new technologies. As for now, the advancement of technology in the field of learning is highly appreciated and anticipated as well. The concerning people have now started to share and exchange their technology hub in order to develop hi-tech communities that is facilitating educational system. Having a fair access to knowledge is indeed a human right. In this regard, advent of augmented and virtual reality education to facilitate learning around the world has helped the students get engaged in experiential learning. The learning is faster, better, retained and has caused at making improved decisions. Industrialization that changed the entire world could have not been possible without technological advancement and innovation. Virtual reality technology comes under the expertise of next generation that will benefit both the educators and the learners.
\end{abstract}

Keywords: Interactive Technology, industry of education, Augmented-Virtual Reality.

Cite this Article: Dr. Mirza Viquar Ahmed, Multisensory Flow Experience through Augmented-Virtual Reality Interactive Technology Education, International Journal of Advanced Research in Engineering and Technology, 10 (5), 2019, pp 49-54.

http://iaeme.com/Home/issue/IJARET?Volume=10\&Issue $=5$

\section{INTRODUCTION}

The industry of education has appeared to be found as little bit slow at embracing the effectiveness and usefulness of new technologies. As for now, the advancement of technology in the field of learning is highly appreciated and anticipated as well. The concerning people have now started to share and exchange their technology hub in order to develop hi-tech communities that is facilitating educational system. Having a fair access to knowledge is indeed a human right. In this regard, advent of augmented and virtual reality education to facilitate learning around the world has helped the students get engaged in experiential learning. The learning is faster, better, retained and has caused at making improved decisions. Industrialization that changed the entire world could have not been possible without technological advancement and innovation. Virtual reality technology comes under the expertise of next generation that will benefit both the educators and the learners. Above all the 
advantages of augmented reality technology and virtual reality technology, they have made education as affordable in the world where most of the people have been affected by increasing rate of inflation. Hence, education is affordable now and is accessible at the same time. This paper attempts to assess the implications of multisensory flow experience through augmented-virtual reality interactive technology education.

\section{IMPLICATION OF VR IN TODAY'S CLASSROOM}

According to Margaryan, Littlejohn and Vojt (2011), virtual reality technology or VR is a factual advancement of technology that has created multisensory, immersive nature of experiences while having the needed potential of changing the entire mode of learning like forever. It has provided the educators with a subtle way of transporting the students from inside of their school walls and engaging them in some unique kind of leaning. Merchant, Goetz, Cifuentes, Keeney-Kennicutt and Davis (2014) relate it most interestingly that a geography teacher can take her students on a trip to Niagara Fall and history teacher can take her students back in the time of stones. This shows that a single technology can be used to take advantage in a variety of manner.

However, this very technology is not about creating experiences only but also facilitates the students to acquire understanding of complex terms and theories and so is adding on to the current methods of teaching. In case of a science lesson, VR is practically effective. As per the knowledge shared by Carrozzino and Bergamasco (2010), there are a number of lessons in science that can only be conceptualized, even some great and creative presentations do not seem to justify the wonders of space. With the help of VR technology, students are able to investigate the impact of radioactive materials in chemistry without being exposed to any health risk. They can see into the body of a human without actually operating a person.

\section{CLASSROOM-TO-WORKPLACE}

In the world of business, a number of companies have already adopted their commitment with educational advantages of VR. However, they are not only technology-oriented companies like Google but most recently L'Oreal has successfully launched their 'VR hair education salon' for their stylists.

The new technologies have enabled to have substantial amount of impact on how majority of businesses address the challenges since the actual potential of VR has been just begun to be analysed (Margaryan, Littlejohn \& Vojt, 2011). Just by integrating technology of 21 st century into the classroom and making it a part of core value can help educators own the technology by teachers and students both. Most sadly, a real pedagogical shift is required among teachers especially as to learn to use application of VR in educational world.

Carrozzino and Bergamasco (2010) believe that VR offers innovative mays of guiding students to understand some very complicated topics and providing them with real meaningful engagement with their lessons and classes (Merchant et.al, 2014). This is definitely significant that digital giants at schools should make unconditional efforts to promote education implications of VR (and AR). This will help them deliver teaching experiences successfully meeting the needs of today's learners.

\section{AR EXPERIENCES AND IMPLICATIONS}

Several modern teachers as a part of Generation $\mathrm{X}$ had been asked to share their idea and opinion about learning objects out of their classroom in 80's and 90's. They appeared to recall only paper, pencil, blackboards and textbooks. Later a series of pictures of 70's, 80's and 90's classroom were shown to them in order to have them described. They were able to say as "utilitarian, boring and two-dimensional". 
Barfield (2015) says that Augmented Reality or AR has attained much acceptance on the account of recent advancement of technology yet a learning experience only. However, it is able to represent more than a mere integration of hardware, software and relevant information in the context. This can be termed as a 'concept' when is applied to educational implications besides making any certain combination of technologies.

Once AR has been defined as a concept this enables the use of broad array of hardware, software as well as design strategies (Di Seri, Ibáñez \& Kloos, 2013). These intently inspire the local development of contextually pertinent AR learning experiences. Besides, it is quite imperative to adopt a specific way to define AR that

should qualify it to be revised and reformed as to fit into the local instructional and curricular requirements and demands. Gauging AR with respect to its adoption as innovation implies towards the fact that perceived compatibility absolutely lays promising impact on the rate of adoption. In addition to this, a conceptual definition appears to be much more compatible since it can carry the potential to afford curricular flexibility, hardware and software flexibility all at the same time. This aims at facilitating the instructors at incorporating AR in their system design (Barfield, 2015).

The classrooms today is at part at making use of AR in order to develop the web of digital natives for the generation (Di Seri, Ibáñez \& Kloos, 2013). Nowadays, pupils have the liberty to walk into their classrooms and operate their tabs (tablets) or smartphones since the AR device to activate to verbal content developed on software of movie-making and later posted onto YouTube. This eventually leads to taking place of immediate and immersive learning experience (Hew \& Cheung, 2010). In modern classrooms today, it is interesting to find that even the sound of learning has been changed from teacher's vocal command of directing pupils towards pupil's sound of working as a group member while listening to the content (audio or visual) using their devices (through ear phones). Students are actively 'doing' than just passively listening as per the opinion made by Jeff Gorman who is the Assistant Superintendent of Schools in Monroe Township, New Jersey, and regularly observes the forward-looking classrooms. According to him it is no more a query as to what has the teacher taught today but what interesting thing could you discover at school today. This specifies a clear shift in the process of learning towards achieving skills of higher level thinking (Di Seri, Ibáñez \& Kloos, 2013).

Technology Integration Specialist, Meg Wilson at Avenues shares his opinion that by incorporating AR in her classroom has caused to develop a new and another dimension to overall learning of the students. This helps to redefine AR as a strategic partner for developing a conducive learning environment where not only pupils are learning and facing the challenges but the educators as well have to make their genuine efforts to embrace technology (Hew \& Cheung, 2010).

\section{AR/ VR SOLUTION FASTER LEARNING}

Learners of three modalities like kinaesthetic, visual and auditory receive due advantages of AR and VR on the account of sensory and experiential implication of the technology. They are able to acquire 'learning' at a faster pace while at the same time be able to develop higher level of cognitive skills. According to Di Seri, Ibáñez and Kloos (2013), AR and VR are the technologies that have all the required potential to drastically expand the knowledge of a person and hence improve the cognitive abilities and skills. A bridge that is existing between this physical world and the world of virtual objects and interfaces tend to add on a level of abstract reality. It needs to be stated here that virtual reality should not be considered as a new concept since its applications have already been realized and implemented in game, field of 
architecture, medicine and most popularly construction. Both technologies have been modified to be applied in the making learning possible and enrich multimodal learning. The later does not only enhance but promotes effective and meaningful experiences. However, this has mostly been observed that any technology that is used for educational purpose has to go through much speculation regarding its uses, applications, limitations, and affordability.

Novelty of learning has to be secured in any case. Tools are the natural part of human evolution that are forming the foundation of human ability as to expand inborn human capabilities. In this regard, cognitive tools enable the pupils to improve, extend and enrich their cognition by using computer-based tools. Such tools tend to facilitate the process of knowledge construction and have the potential to extend support and guidance to widen human thought process. According to Mikropoulos and Natsis (2011), the peculiarity and difference lying between 'learning from technology' versus 'learning with technology' aims to define and redefine technology as a cognitive tool. The application of AR and VR in the form of cognitive tool presents with opportunities to expand on the mental capacity like memory, visualization and imagination by using virtual objects and interfaces (Mikropoulos \& Natsis, 2011). This very idea enable a learner to make use of higher order thinking skills without much efforts. Here the higher order skills include problem solving and critical thinking. It implies towards the uniqueness of the tools to change human perception for the world by rearranging the representation of objects in the environment.

\section{HIGHER LEVEL KNOWLEDGE TRANSFER}

AR and VR education solutions facilitate the learners to learn-by-doing since they expose the learner to interactive detailing and gives them immersive interactive experience.

According to Hew and Cheung (2010), this is a sort of learning transition that have been moved from traditional memorization. This gives the learners an opportunity to acquire the ability to apply and analyze their knowledge. This eventually improves their creativity, critical, thinking and communication.

\subsection{Having Less-Doing More}

The trends show that strength of the students in classes is drastically increasing, besides, the amount of content that is ought to be retained by the students is increasing as well. The budget is not as promising as required for which educators have to look for solutions to help teachers with lesser time and monetary support. Chang, Morreale and Medicherla (2010) emphasize that the teachers have to be facilitated so that they can teach efficiently to promote better retention within limited personal attention.

\subsection{Job-readiness}

The dire ability or the skills among the school leavers is highly appreciated by the corporate world that can help them apply creativity, think critically and arrive at solutions. Today's business world is also quite challenging and demands to have ability in a person to think critically and suggest way outs. In relation to this mere memorization and recalling is not enough to meet alien sort of challenges one may encounter on job.

According to the research made by Chang, Morreale and Medicherla (2010), there many sensible ways in which AR and VR learning solutions provide remedy to the above mentioned problems.

E-E Learning. This means efficient and effective learning. Whenever someone is creating any application of AR or VR, he is actually engaged in kinesthetic, visual and auditory learning experience at a same time. This eventually leads to having faster, increased retention and reasoning ability. 
Thinking v. Memorization. AR and VR education solutions help the pupils to experience practical learning and engagement through interactive experiencing. The risk factor is nil (mostly) and so the students can use a variety of methods or even invent one while learning some new concoct.

Span-Quality of Attention. Too many distractions make it hard for the learners to even have a grasp on the knowledge. In addition to this, most of these distraction are too appealing in comparison to students' classwork. AR and VR genuinely create a viable environment that provokes student to actively participate and keep their enthusiasm intact for learning (Yuen, Yaoyuneyong \& Johnson, 2011). It is almost addictive to use with creative and innovative ways than having plain traditional learning.

\section{ATTENTION THROUGH GREATER LEVEL OF ENGAGEMENT}

As per the Code of Learning by the American educationist, Edgard Dale, in a span of two weeks a human brain retains only $10 \%$ of what he reads, $20 \%$ of what he hears yet $90 \%$ of whatever he does or simulates. The educational solutions and out of the application of RA and VR develop a certain environment that helps students actively participate in improving their learning and constructing better learning material while are incorporated through assessments and ramifications.

1. Immersion is a way that provoke the learning ability of the students. Virtual environment can be representing invisible and manipulative forms and concept that may be intangible in the real world. Certain said activities incite the pupils to gain direct experience rather than seeing through the eyes of their instructors (Yuen, Yaoyuneyong \& Johnson, 2011).

2. The education provides have always talked about the significance of interaction for the students to learn better. Induction of interactive systems in the system of learning makes the students become active thinkers from passive observers. Virtual interactions in virtual environment results in attaining the needed effective and comprehensive responses.

3. The use of this technology brings among the students a sense of experiencing empowerment that makes virtual environment unique. Here the students are able to control the computer and do their bidding in a subtle manner (Yuen, Yaoyuneyong \& Johnson, 2011). This may get intrigued as a result of well-designed virtual environment.

\section{CONCLUSIONS / FINDINGS}

Empirical results indicate towards the existence of three decorating psychological states; sense of body ownership, sense of ownership control and self-explorative engagement that is directly inducing a multisensory flow experience. Moreover, two multisensory elements; sense of self-location and haptic imagery have intermediated the experience via the above mentioned decorating psychological states. VR carries all the potential to be able to bring improvement in the capacity of human mind by improving memory. This memory improvement focuses supremely on retaining the learned facts for a longer period of time. VR tends to cater to the demand of simulation effectively while students can have interaction with virtual environment and are able to manipulate objects in a variety of manner. This actually supports the concept of 'learning by doing' and come up with creativity by constructivism. Technological advancements including proliferation of smartphones, access to modern apps and development of cost-effective devices in the field of business makes it thinkable to be applied for teaching and learning in reality. Besides, the using AR and VR as cognitive tools tends to engage and improve cognitive abilities of the pupils. Using AR and VR to support to acquire higher order thinking skills confirms the effectiveness of the technology. They are 
used to provide cognitive scaffolds or frames with the help of which students are able to build their conceptual understanding of abstract concepts by making interaction with virtual objects. There are now some new affordable applications of AR and VR in the field of games and entertainment, in addition to this, proliferation learning-oriented software and apps will soon lead to realizing the significance of virtual reality for learning as well.

\section{REFERENCES}

[1] Barfield, W. (Ed.), Fundamentals of wearable computers and augmented reality. CRC Press. Carrozzino, M., \& Bergamasco, M. (2010). Beyond virtual museums: Experiencing immersive virtual reality in real museums. Journal of Cultural Heritage, 11(4), 2015, pp 452-458.

[2] Chang, G., Morreale, P., \& Medicherla, P, Applications of augmented reality systems in education. In Proceedings of society for information technology \& teacher education international conference Chesapeake, VA: AACE,Vol. 1, 2010, pp. 1380-1385

[3] Di Serio, Á, Ibáñez, M. B., \& Kloos, C. D, Impact of an augmented reality system on students' motivation for a visual art course. Computers \& Education, 68, 2013, pp 586-596.

[4] Hew, K. F., \& Cheung, W. S, Use of three-dimensional (3-D) immersive virtual worlds in K12 and higher education settings: A review of the research. British journal of educational technology, 41(1), 2010, pp 33-55.

[5] Margaryan, A., Littlejohn, A., \& Vojt, G, Are digital natives a myth or reality? University students' use of digital technologies. Computers \& Education, 56(2), 2011, pp 429-440.

[6] Merchant, Z., Goetz, E. T., Cifuentes, L., Keeney-Kennicutt, W., \& Davis, T. J, Effectiveness of virtual reality-based instruction on students' learning outcomes in K-12 and higher education: A meta-analysis.Computers \& Education, 70, 2014, pp 29-40.

[7] Sarath Sasank, Nisha V. M, Sajidha S. A, Bharadwaja Kumar, Urban Growth Modelling Using Cellular Automata Based Classifier, International Journal of Civil Engineering and Technology, 8(12), 2017, pp. 316-323.

[8] Bharath V G and Dr. Rajashekar Patil. Virtual Reality for Metal Arc Welding: A Review and Design Concept. International Journal of Mechanical Engineering and Technology, 8(1), 2017, pp. 132-138.

[9] K. Rajathi, R.Vinoth Kumar and G.Tamilmani, A Pedagogical Approach for Engineering Education, International Journal of Civil Engineering and Technology, 8(10), 2017, pp. 343349.

[10] A. Manikandan and M. Muthumeenakshi, Role of Engineering Education in Sustaining the Economic Development of India, International Journal of Mechanical Engineering and Technology 9(3), 2018, pp. 706-710.

[11] Mrs. Varsha H. Patil and Mrs. Snehal M. Kamalapur, a Conceptual Thinking of Total Quality Management in Engineering Education, Volume 3, Issue 1, January- April (2012), pp. 169174

[12] Mikropoulos, T. A., \& Natsis, A, Educational virtual environments: A ten-year review of empirical research (1999-2009). Computers \& Education, 56 (3), 2011, pp 769-780.

[13] Sarath Sasank, Nisha V. M, Sajidha S. A, Bharadwaja Kumar, Urban Growth Modelling Using Cellular Automata Based Classifier, International Journal of Civil Engineering and Technology, 8(12), 2017, pp. 316-323.

[14] Yuen, S., Yaoyuneyong, G., \& Johnson, E, Augmented reality: An overview and five directions for AR in education. Journal of Educational Technology Development and Exchange, 4(1), 2011, pp 119-140. 